\title{
Occupational therapy students' use of social media for professional practice
}

D Naidoo, PhD; P Govender, PhD; M Stead, BOT; U Mohangi, BOT; F Zulu, BOT; M Mbele, 4th-year OT student

Discipline of Occupational Therapy, School of Health Sciences, University of KwaZulu-Natal, Durban, South Africa

Corresponding author: D Naidoo (naidoodes@ukzn.ac.za)

Background. The use of social media for professional practice is an emerging trend for healthcare professionals; however, limited literature exists on the phenomenon. Social media usage is prevalent among students, as it is incorporated into many health professions education curricula. This poses potential ethical dilemmas.

Objective. To examine the nature of social media usage and knowledge of ethical considerations by occupational therapy (OT) students for professional purposes.

Methods. A quantitative, cross-sectional survey was administered to the entire cohort of OT students $(N=128)$ enrolled at the University of KwaZuluNatal, Durban, South Africa in 2016. Data were analysed descriptively using Microsoft Excel 2013 (Microsoft, USA).

Results. The most commonly used device to access social media was mobile phones, with WhatsApp and YouTube frequently used for both general and professional purposes. Uses included accessing social media for developing professional skills and knowledge, and in fulfilling academic requirements. Ethical dilemmas were evident among students, who indicated that social media ethical considerations should be incorporated into the curriculum.

Conclusion. The study highlighted that most students use some form of social media as part of their professional practice, which has the potential to be used effectively to enhance learning opportunities. Future studies of a qualitative nature could shed light on students' perceptions of social media and practical implications for practice.

Afr J Health Professions Educ 2018;10(2):101-105. DOI:10.7196/AJHPE.2018.v10i2.980

Internet-based applications are changing the manner in which we communicate and circulate professional and personal information. ${ }^{[1]}$ Improved connectivity and access to the internet have enabled people to instantaneously share ideas and interact with others on a global scale. ${ }^{[2,3]}$ Ventola $^{[4]}$ highlighted the potential use of social media to foster understanding of the occupational therapy (OT) profession and to promote various health behaviours or fund-raising opportunities. ${ }^{[4]}$ For the purpose of this study, social media are defined as 'digital technologies and practices that enable people to use, create and share content, opinions, insights, experiences and perspectives, build relationships and promote discussion. ${ }^{[5]}$ This includes the use of discussion groups using messaging software, such as WhatsApp. The World Federation of Occupational Therapy (WFOT) position paper ${ }^{[6]}$ on social media use highlights the role that social media can play in continuing professional development and enhancing networking within OT. The paper cites gathering information, improving practice and networking for knowledge development as examples of acceptable professional practice use of social media. ${ }^{[6]}$

There is a growing trend of incorporating social media for professional purposes into health professions education. Snyman and Visser, ${ }^{[7]}$ in a South African (SA) study comprising 344 dentists, established that social media are being used as a marketing tool. Pearson et al. ${ }^{[8]}$ used an online survey to explore the use of social media among emergency medicine residents and faculty members at various sites. ${ }^{[8]}$ Potential threats cited included 'breaches of professionalism', which included online disclosure of private information. ${ }^{[7]}$ Variability in the usage trends of social media and concerns about students maintaining clients' privacy were also cited. ${ }^{[7]}$ Despite this article referring to older, qualified professionals, the data highlight potential issues that may arise among students. Given the millennium students' familiarity with social media and technology, there is concern that some of the threats mentioned (breach of professionalism, confidentiality) may be more evident. In contrast, some of the benefits of social media use included more effective communication and interaction among peers, ${ }^{[8]}$ which could have potential positive implications for teaching and student support. Many universities, including the University of KwaZulu-Natal (UKZN), Durban, SA, are moving toward blended learning, which implies the need to explore how students use social media for educational purposes. The absence of literature relating to how OT students use social media during their undergraduate education, highlighted the need for greater insight into how social media can potentially be used to improve learning.

Many policies and guidelines on how to use social media appropriately are still being developed ${ }^{[5,9]}$ as these have to be adapted to include recent advances in technology. ${ }^{[9,10]}$ Pempek et al. ${ }^{[10]}$ suggest that healthcare students and clinicians have difficulty in maintaining a professional persona in the more relaxed setting of social media. Despite the presence of definitions or descriptions for the use of social media in the literature, ${ }^{[6,9,11]}$ there is limited evidence on OT students' views regarding ethical practice during social media use. This article aims to describe the nature of social media usage by undergraduate OT students at UKZN, emphasising the benefits of social media for professional purposes and students' knowledge of ethical considerations when using various social media sites for professional practice. 


\section{Methods}

A cross-sectional survey design was employed. ${ }^{[12]}$ The target population comprised all undergraduate OT students $(N=128)$, through four levels of study, registered in 2016 in the School of Health Sciences at UKZN. A survey was designed through exploration of the current literature and consultation with a biostatistician. The questionnaire comprised four sections, i.e. (i) demographics (including age, gender, level of study, level of information and communication technology (ICT), knowledge and devices on which social media are accessed); (ii) social media use (type of media and frequency of use); (iii) general and professional use of social media; and (iv) ethical considerations regarding the use of social media. The questions were fixed to ensure consistency and reliability. The questionnaire was appraised by a biostatistician, supervisors of the study and a data scientist and matched against the research questions for the study to ensure face and content validity. A pilot study was completed with 34 students (mean age 19.6 years) currently enrolled in the discipline of physiotherapy at UKZN. A number of questions were revised after the pilot study to reduce ambiguity. Data were collected over 2 months. Students were invited to participate during an allocated period. The authors were not present in the session and an academic development officer facilitated administration and collection of the questionnaires. This prevented the influence of possible power differentials. Descriptive statistics were employed to analyse the data with the use of Microsoft Excel 2013 (Microsoft, USA).

\section{Ethical approval}

Ethical clearance was obtained from the Human and Social Sciences Ethics Committee (ref. no. HSS/1117/016U), including gatekeeper permission from the relevant academic leaders.

Written informed consent was obtained from students prior to initiating the study. Principles of autonomy and anonymity and the right to withdraw were observed. ${ }^{[13]}$ The study only explored the use of social media among OT students at UKZN. Furthermore, the survey design did not allow researchers to explore reasons for the use of social media sites.

\section{Results}

The response rate was $83 \%$, with 106 of the 128 questionnaires distributed returned. The sample comprised $90 \%$ females $(n=95)$ and $10 \%$ males $(n=11)$, with a mean age of 22.5 (range 17 - 30) years. The study included 1st-year ( $n=31 ; 29 \%), 2$ 2nd-year $(n=34 ; 32 \%)$, 3rd-year $(n=17 ; 16 \%)$ and 4 th-year $(n=24 ; 23 \%)$ OT students. More than half of the students $(n=62 ; 59 \%)$ had a school level of training in ICT, while $34 \%$ ( $n=36$ ) had no such previous training and $4 \%(n=4)$ had advanced-level training. The same social media account was used for both general and professional purposes by $77 \%(n=82)$ of the students. Mobile phones ( $n=102 ; 96 \%)$, laptops $(n=91 ; 86 \%)$ and desktop computers $(n=57 ; 53.8 \%)$ were the most commonly used devices to access social media. Tablets were used by $50 \%(n=53)$ of the students.

\section{Social media for professional use}

Social media were reported to be an important aspect of students' professional lives. Eightythree percent of 4 th-year, $42 \%$ of 3rd-year, $75 \%$ of 2 nd-year and $74 \%$ of 1 st-year students agreed that social media are an important aspect of professional life. Fig. 1 highlights the various sites used across the four levels of study. WhatsApp, YouTube, Pinterest, Facebook and blogs were used by the majority of students for professional purposes.

There were similar WhatsApp and YouTube usage trends across the years for professional use (Fig. 1). There was a greater use of blogs for professional use by 3rd-year (71\%) and 4th-year (74\%) students than by 1 st-year (13\%) and 2nd-year (22\%) students. There was an increase in professional use of Pinterest from the 1st (6\%) to the 4 th $(77 \%)$ years. Thirty-nine percent of 1 st-year, $39 \%$ of 2 nd-year, $47 \%$ of 3 rd-year and

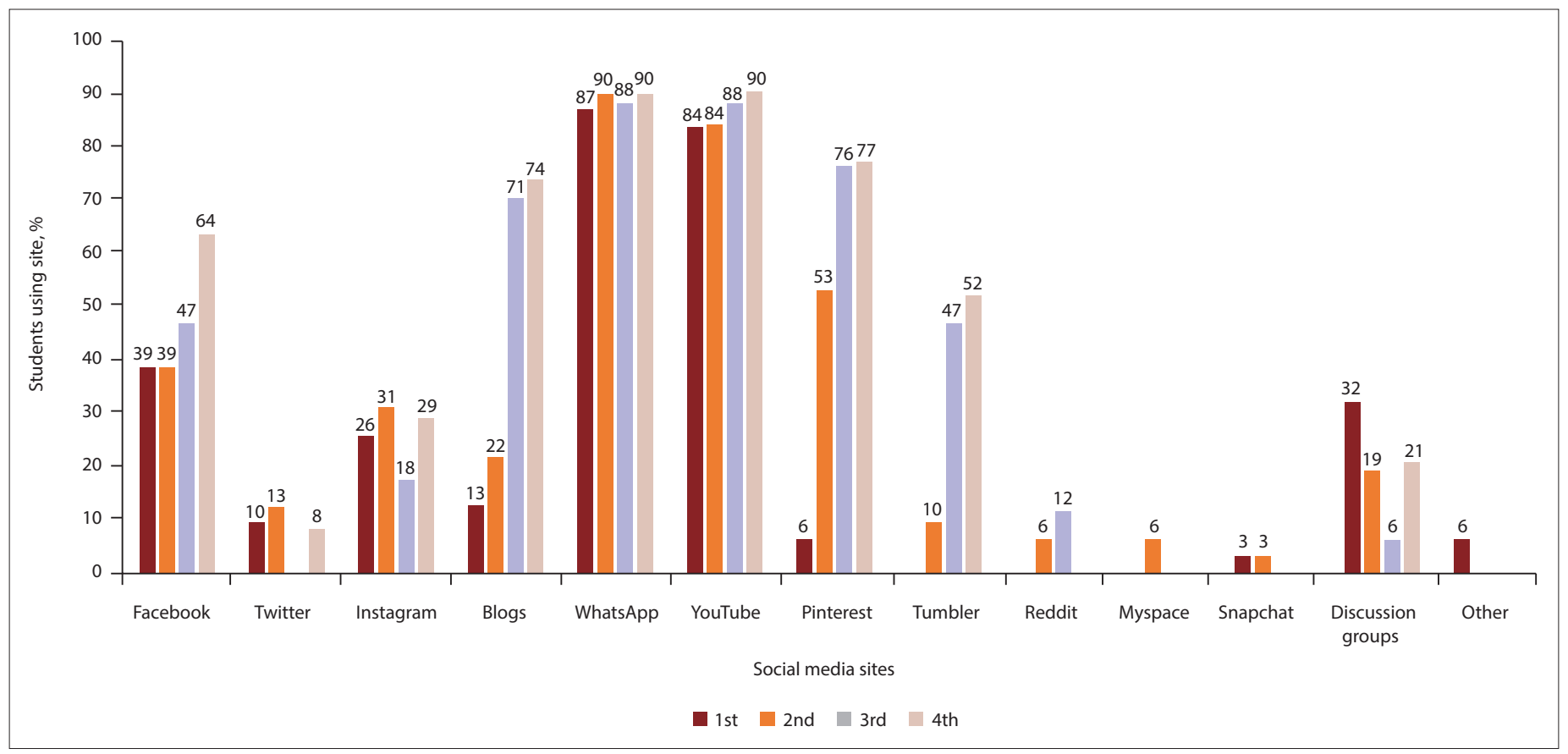

Fig. 1. Social media use for professional purposes $(\mathrm{N}=106)$. 
$64 \%$ of 4 th-year students used Facebook professionally. Despite none of the 1st years using Tumbler professionally, 52\% of the 4 th years used this site professionally. Interestingly, 1st years (32\%) used discussion groups professionally, which was more so than students in any other year. A small percentage of students (6\%) used other social media for professional use, which included Flickr, Vine, Blackberry Messenger and LinkedIn (Fig. 1).

\section{Frequency of social media use for professional purposes}

YouTube and Pinterest had the highest frequency of daily use. Blogs, WhatsApp and Facebook were accessed for professional use at least once a day. Students in all 4 years used WhatsApp most frequently in their daily professional use, with 4th-year students having the highest frequency of use (Table 1).

\section{Professional purpose of social media use}

Fig. 2 highlights the main purposes of social media for professional use by students in this study. These included for academic purposes (78\%), developing skills and knowledge (59\%), improving clinical practice (53\%) and discussion with other professionals (37\%).

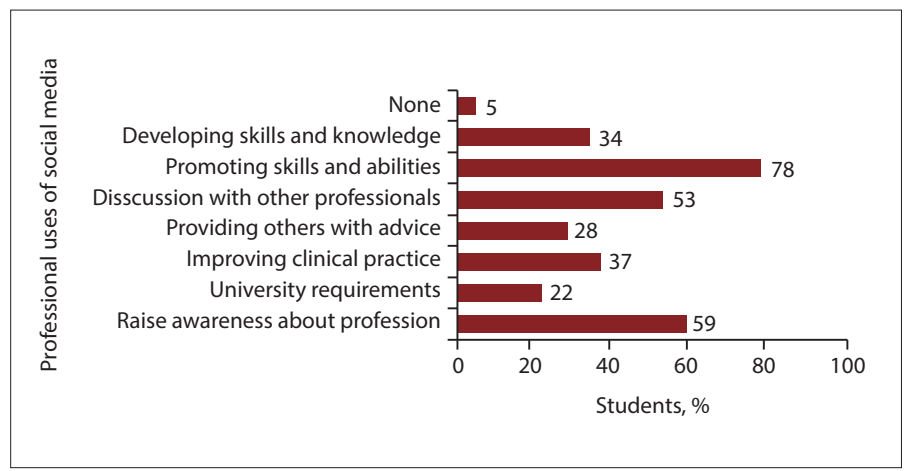

Fig. 2. Professional purpose of social media use by students $(N=106)$.

\section{General v. professional social media use}

When comparing various social media sites, it appears that students use these more often for general than professional purposes, with Facebook, Instagram and Snapchat showing the greatest difference between general and professional use (Fig. 3). Snapchat was used by $38 \%$ of students generally, whereas only $2 \%$ of students used it professionally. Discussion groups were used by $21 \%$ of students generally and by $21 \%$ professionally. Blogs were used by $44 \%$ of students generally and by $39 \%$ professionally. WhatsApp was used by $94 \%$ of students generally and by $86 \%$ professionally (Fig. 3).

\section{Ethical considerations in social media use}

Interestingly, $96 \%$ of students agreed that it is important to consider ethics online when using social media professionally, with $90 \%$ agreeing that poor behaviour online can have an impact on the reputation of the profession. However, only $14 \%$ of students believed that ethical behaviour online is good. Fig. 4 illustrates students' awareness of ethics in this study. Despite $48 \%$ of students being fully aware of ethics and $42 \%$ agreeing that they have been taught about ethics in their studies, $66 \%$ believed that ethics on social media needs to be covered in lectures, especially 3 rd years (77\%) and 4 th

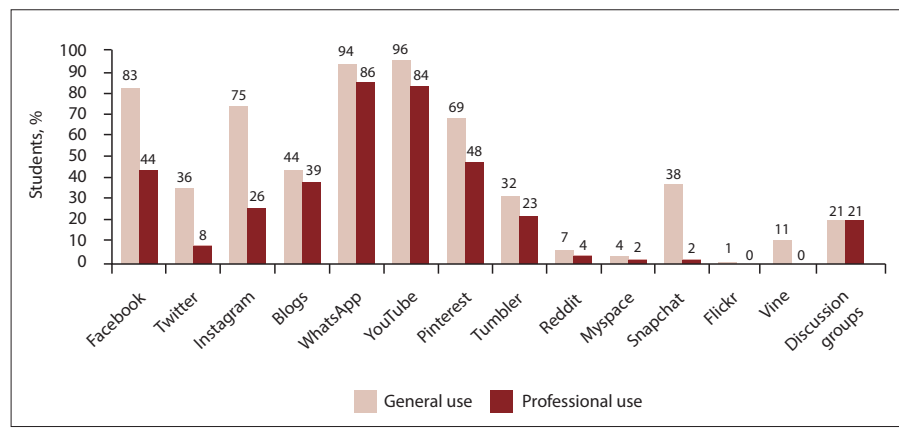

Fig. 3. General v. professional uses of social media sites $(\mathrm{N}=106)$.

Table 1. Frequency of social media use for professional purposes $(N=106)$

\begin{tabular}{|c|c|c|c|c|c|c|}
\hline Student, year & Frequency & Facebook, \% & Blogs, \% & WhatsApp, \% & YouTube, \% & Pinterest, \% \\
\hline \multirow[t]{4}{*}{1 st } & Rarely & 16 & 6 & 0 & 10 & 0 \\
\hline & Monthly & 10 & 3 & 6 & 13 & 3 \\
\hline & Weekly & 10 & 3 & 23 & 19 & 0 \\
\hline & Daily & 3 & 0 & 58 & 42 & 3 \\
\hline \multirow[t]{4}{*}{ 2nd } & Rarely & 13 & 13 & 3 & 3 & 3 \\
\hline & Monthly & 10 & 3 & 3 & 16 & 19 \\
\hline & Weekly & 6 & 3 & 30 & 25 & 22 \\
\hline & Daily & 10 & 3 & 53 & 41 & 9 \\
\hline \multirow[t]{4}{*}{3 rd } & Rarely & 18 & 12 & 0 & 0 & 0 \\
\hline & Monthly & 0 & 53 & 12 & 35 & 41 \\
\hline & Weekly & 18 & 6 & 12 & 29 & 24 \\
\hline & Daily & 12 & 0 & 65 & 24 & 12 \\
\hline \multirow[t]{4}{*}{4 th } & Rarely & 9 & 9 & 0 & 10 & 9 \\
\hline & Monthly & 14 & 30 & 0 & 43 & 27 \\
\hline & Weekly & 32 & 35 & 5 & 24 & 32 \\
\hline & Daily & 9 & 0 & 85 & 14 & 9 \\
\hline
\end{tabular}


years (76\%). Distinctively, 4th-year students (17\%) reported feeling the least aware of ethics (Fig. 4).

\section{Discussion}

The SA internet user population reached 20 million in 2016. ${ }^{[14]}$ Gikas and Grant ${ }^{[15]}$ found that $67 \%$ of 10000 students used their mobile phones for the majority of their academic activities. Similarly, Goldstuck's ${ }^{[16]}$ SA study found that students felt that social media enhance their academic and social lives. OT students at UKZN use social media for both general and professional purposes. As noted in the literature, ${ }^{[17-20]}$ WhatsApp, Facebook and Instagram were the most commonly used social media sites in this study. WhatsApp, YouTube, Facebook and Pinterest were all commonly used by the students for professional purposes. WhatsApp appears to be popular owing to the speed of communication, which includes the ability to share text messages, pictures and voice notes rapidly. ${ }^{[16]}$ Mohapatra et al. ${ }^{[21]}$ identified that the use of software applications, such as WhatsApp, has the potential to enhance communication in healthcare and medical education. There is evidence that students use social media for educational purposes, which corresponds with that in the current literature. . $^{[2,7,9,10]}$

Lui et al.' $\mathrm{s}^{[22]}$ systematic review highlighted that blended learning (face-toface and e-learning) has a positive effect on learning in higher education. ${ }^{[22]}$ The participants noted that fulfilling university requirements, developing skills and knowledge and improving clinical practice were the main reasons for professional social media use. Gikas and Grant ${ }^{[15]}$ described social media as an open environment where ideas can grow online. YouTube and Facebook have both been found to be useful sites for content sharing within academic institutions. ${ }^{[23]}$ For example, Facebook has been used to start health science special interest/discussion groups, while YouTube enhances learning by providing additional content from an outsider's perspective. ${ }^{[23]}$ In our study, there was a decline in the frequency of YouTube use as students progressed to their final year. The highest frequency of usage occurred in 1st and 2nd years. This finding could be owing to 1st- and 2nd-year students still seeking foundational knowledge. Additionally, YouTube videos have been used to enhance clarification of difficult concepts, especially in subjects such as anatomy and physiology. Jaffar et al. ${ }^{[24]}$ found that $98 \%$ of students used YouTube as an online information resource to enhance their understanding of human anatomy.

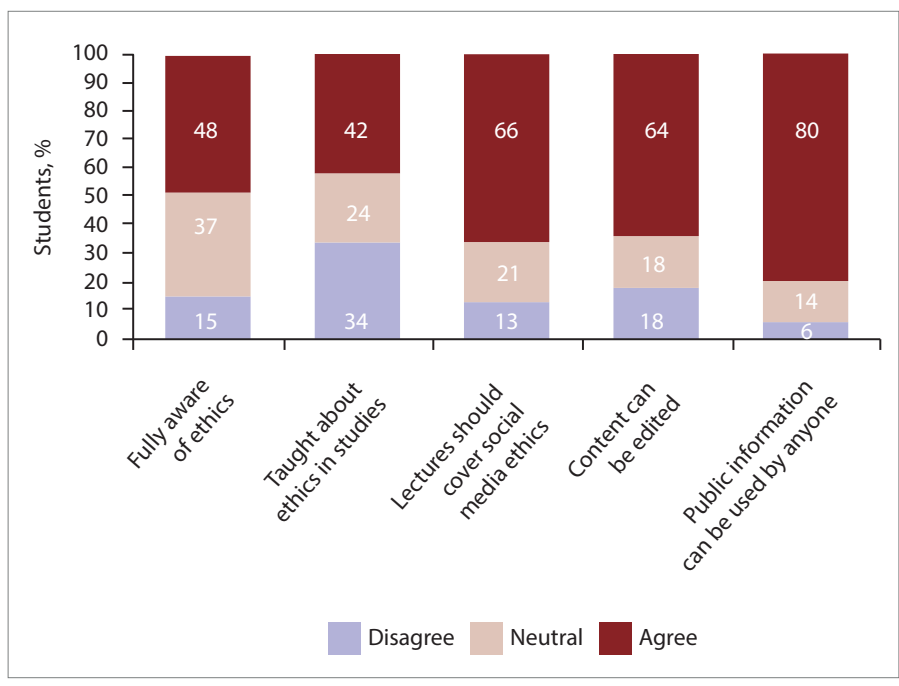

Fig. 4. Students' awareness of ethics ( $\mathrm{N}=106)$.
Pinterest, a digital pinboard, has gained rapid popularity. WFOT acknowledged Pinterest in their position statement on social media usage. ${ }^{[6]}$ Despite Pinterest mainly being used as a social tool, business and education have shown much interest in it. ${ }^{[21]}$ The social and visual aspects of Pinterest make it extremely appealing to educators, as it has the potential to provide learning opportunities for students. ${ }^{[25]}$ The current study noted an increase in the frequency of Pinterest use, as students progressed from 1st to final year. This could be attributed to the increase in students' exposure to service-learning settings; hence the need to generate creative ideas when planning intervention sessions.

Blogs have been used for teaching and learning purposes and to share lessons with colleagues. ${ }^{[2,26]}$ In this study, the higher usage of blogs by 3rd- and 4th-year students could be accredited to these students needing to complete a blog as part of their service-learning modules. The reflective practice inherent in writing blogs serves to deepen students' experiences during professional practice. Discussion groups appeared to be more common among 1st-year students than students in any other year. This could be because younger generations are interested in gaining knowledge from online sources.

Despite the benefits gained through the use social media, there is a risk of unethical practice. Some risks include the blurring of professional and social boundaries, breaching patients' privacy and confidentiality (especially with taking or sharing pictures or information) and damaging the public image of the profession. ${ }^{[27,28]}$ Students reported that even though ethics is covered in lectures, ethics specifically focusing on social media use requires further input. Despite WFOT recently introducing a position statement on the principles of good practice when engaging in social media for professional practice, ${ }^{[6]}$ ethics in social media has been largely neglected. Even the Health Professions Council of SA has not included online ethics in their ethical guidelines. $^{[29]}$

WFOT guidelines include the setting of a clear boundary when individuals speak for themselves and when they speak for the profession, understanding that the image presented online represents both the individual and the profession and therefore treating others on a public platform with consideration. ${ }^{[6]}$ Although this position paper provides individuals in the OT profession with good social media principles, there is lack of detail as what exactly good ethical conduct online constitutes, especially around what can be shared on social media. The current cohort of OT students have been accustomed to social media use in their personal capacity (59\% used social media in school) and may not be cognisant of what constitutes a breach of confidentiality or privacy with regard to patients. Ethical considerations are fundamental concepts that students must learn, as they need to be accountable for their online posts and can be legally bound to uphold standards of professional practice. ${ }^{[28,30]}$ At UKZN, final-year OT students use social media to convey information to patients and their caregivers about home programmes and reflect on their practice in blogs. However, they reported feeling less aware of ethics than the 1st- and 2nd-year students, which may be attributed to 4th-year students experiencing ethical dilemmas in real-life situations during service-learning placements and feeling inadequately equipped to translate the theory they learnt during their 1st year into practice. Students need to have a wellestablished understanding of the ethical practice around social media use to prevent breaches of confidentiality or blurring of professional and personal boundaries. Chretien and $\mathrm{Kind}^{[31]}$ described the inability to maintain a professional persona in the more relaxed setting of social media. 
In Ventola's ${ }^{[4]}$ study, $68 \%$ of both practising and student physicians felt it was ethically problematic to interact with patients on social networks for either personal or professional reasons. However, $56 \%$ of patients wanted their physicians to use social media for activities such as scheduling appointments and answering general questions about their conditions. ${ }^{[5]}$ This highlights the challenge of negotiating between meeting patients' needs and following ethical guidelines. There is a need for the establishment of clear ethical guidelines from professional bodies to protect both the healthcare practitioner and patient and for health professions programmes to ensure that 2nd - 4th-year students have sufficient opportunities for lectures and discussions on social media ethics.

\section{Conclusion}

This quantitative, cross-sectional study was conducted to determine the nature of social media usage and ethical awareness among a cohort of OT students. Sites such as WhatsApp, YouTube and Facebook appeared to be more popular in this particular context. The study has highlighted the important role that social media play in many students' professional lives, with a variety of sites being used for fulfilling university requirements and improving clinical practice. Another vital area highlighted was the challenges of ethical practice and social media use. Students appeared to have some awareness of ethical considerations. However, many students lacked awareness of policies, guidelines and legislation that relate to their online usage, thereby placing them at risk of overstepping boundaries and incurring legal implications. The authors therefore believe that social media need to be covered in ethics lectures and measures have to be put in place to ensure that policies, procedures and guidelines are adhered to. We therefore suggest that this study be used as a starting point for further studies into the extent of the benefits of social media for professional practice.

Acknowledgements. The authors would like to acknowledge the participants in the study.

Author contributions. DN and PG were responsible for the conceptualisation and supervision of the study, as well as for the drafting and revision of the manuscript. MS, UM, FZ and MM were involved in the execution of the study and the analysis and drafting of the manuscript.

Funding. None.

Conflicts of interest. None.
1. Dieleman C, Duncan EAS. Investigating the purpose of an online discussion group for health professionals: A case example from forensic occupational therapy. BMC Health Serv Res 2013;13(1):253. https://doi.org/10.1186/1472 6963-13-253

2. Ezzamel S. Blogging in occupational therapy; knowledge sharing, professional development, and ethica dilemmas. Br J Occup Ther 2013;76(11):515-517. https://doi.org/10.4276/030802213X13833255804711 3. Sau K. Netiquette: A modern day essential for occupational therapists. Ind J Occup Ther 2013;45(3):26. 4. Ventola CL. Social media and health-care professionals: Benefits, risks and best practices. Pharm Ther 2014;39(7):491-520. 5. College of Occupational Therapists of Ontario. Practice guideline: Using social media. http://www.coto.org/pdf/ Guidelines_UseofSocialMedia.pdf (accessed 2 August 2017).

6. World Federation of Occupational Therapy. Position paper: Use of social media. 2016. http://www.wfot.org/ 6. World Federation of Occupational Therapy.
ResourceCentre.aspx (accessed 2 May 2017).

7. Snyman L, Visser JH. The adoption of social media and social media marketing by dentists in South Africa. S Afr Dent J 2014;69(6):258-264.

8. Pearson D, Bond MC, Kegg J, et al. Evaluation of social media use by emergency medicine residents and faculty. West J Emerg Med 2015;16(5):715. https://doi.org/10.5811/westjem.2015.7.26128

9. Landman MP, Shelton J, Kauffmann RM, Dattilo JB. Guidelines for maintaining a professional compass in the era of social networking. J Surg Educ 2010;67(6):381-386. https://doi.org/10.1016/j.jsurg.2010.07.006

10. Pempek TA, Yermolayeva YA, Calvert SL. College students' social networking experiences on Facebook. J Appl Develop Psychol 2009;30(3):227-238. https://doi.org/10.1016/j.appdev.2008.12.010

11. Wu WH, Wu YC, Chen CY, Kao HY, Lin CH, Huang SH. Review of trends from mobile learning studies: A metaWu WH, Wu YC, Chen CY, Kao HY, Lin CH,
analysis. Comput Educ 2012;59(2):817-827.

12. Lavrakas PJ. Encyclopedia of Survey Research Methods. Thousand Oaks, CA: SAGE, 2008

13. World Medical Association. Declaration of Helsinki. Ethical principles for medical research involving human subjects. 2008. http://www.wma.net/e/policy/b3.Htm (accessed 23 March 2018).

14. Goldstuck A. SA internet penetration to reach 40\% in 2017. https://www.worldwideworx.com (accessed 23 March 2018).

15. Gikas J, Grant MM. Mobile computing devices in higher education: Student perspectives on learning with cell-phones smartphones and social media. Internet High Educ 2013;1(19):18-26. https://doi.org/10.1016/j.i.heduc.2013.06.002

16. Goldstuck A. SA high-tech student. 2013. https://www.worldwideworx.com/hightech-student (accessed 6 September 2017).

17. Snyman A. Social media - the latest South African stats. 2016. https://www.webafrica.co.za/blog/social-media-2 social-media-latest-south-african-stats/ (23 September 2016).

18. Sponcil M, Gitimu P. Use of social media by college students: Relationship to communication and self-concept. J Technol Res 2013;1(4):1.

19. Verdonck MC, Ryan S. Mainstream technology as an occupational therapy tool: Technophobe or technogeek? Br J Occup Ther 2008; $71(6): 253-256$

20. Gilbert S. Learning in a Twitter-based community of practice: An exploration of knowledge exchange as a motivation for participation in \#hcsmca. Inform Commun Soc 2016;19(9):1214-1232. https://doi.org/10.1080/ 1369118X.2016.1186715

21. Mohapatra DP, Mohapatra MM, Chittoria RK, Friji MT, Kumar SD. The scope of mobile devices in health care and medical education. Int J Adv Med Health Res 2015;2(1):3.

22. Lui Q, Peng W, Zhang F, Hu R, Li Y, Yan W. The effectiveness of blended learning in health professions: Systematic review and meta-analysis. J Med Internet Res 2016;18(1):e2. https://doi.org/10.2196/jmir.4807

23. George DR, Dellasega C. Use of social media in graduate-level medical humanities education: Two pilot George DR, Dellasega C. Use of social media in graduate-level medical humanities education: Two pilot
studies from Penn State College of Medicine. Med Teach 2011;33(8):e429-e434. https://doi.org/10.3109/01421 59X.2011.586749

24. Jaffar AA. YouTube: An emerging tool in anatomy education. Anat Sci Educ 2012;5(3):158-164. https://doi. org $/ 10.1002 /$ ase. 1268

25. Hansen K, Nowlan G, Winter C. Pinterest as a tool: Applications in academic libraries and higher education. Can J Libr Inform Pract Res 2012;7(2). https://doi.org/10.21083/partnership.v7i2.2011

26. Cain J, Scott DR, Tiemeier AM, Akers P, Metzger AH. Social media use by pharmacy faculty: Student friending e-professionalism, and professional use. Curr Pharm Teach Learn 2013;5:2-8.

27. Nyangeni T, du Rand S, van Rooyen D. Perceptions of nursing students regrading responsible use of social media Nyangeni T, du Rand S, van Rooyen D. Perceptions of nursing students regrading resp
in Eastern Cape. Curatonis 2015;38(2). https://doi.org/10.4102/curationis.v38i2.1496

28. Grobler C, Dhai A. Social media in healthcare context: Ethical challenges and recommendations. S Afr J Bioethics Law 2016;9(1):22-25. https://doi.org/10.7196/SAJBL.2016.v9i1.464

29. Health Professions Council of South Africa. Guidelines for good practice in the healthcare professions: General ethical guidelines for the healthcare professions. http://www.hpcsa.co.za/Uploads/editor/UserFiles/downloads/ conduct_ethics/Booklet\%201.pdf (accessed 8 March 2016).

30. Helm J. Ethical and legal issues related to blogging and social media. J Acad Nutr Diet 2013;113(5):688-690.

31. Chretien KC, Kind T. Social media and clinical care. Circulation 2013;127(13):1413-1421. https://doi.org/10.1161/ CIRCULATIONAHA.112.128017

Accepted 12 October 2017 